\title{
PERSPECTIVES
}

\section{Moving from Evidence-Based Medicine to Evidence-Based Health}

\author{
David Moskowitz, $M D^{7}$ and Thomas Bodenheimer, $M D^{2}$
}

'Division of General Internal Medicine, University of California San Francisco, San Francisco General Hospital, San Francisco, CA, USA; ${ }^{2}$ Center for Excellence in Primary Care, Department of Family and Community Medicine, University of California San Francisco, San Francisco, CA, USA.

While evidence-based medicine (EBM) has advanced medical practice, the health care system has been inconsistent in translating EBM into improvements in health. Disparities in health and health care play out through patients' limited ability to incorporate the advances of EBM into their daily lives. Assisting patients to self-manage their chronic conditions and paying attention to unhealthy community factors could be added to EBM to create a broader paradigm of evidence-based health. A perspective of evidence-based health may encourage physicians to consider their role in upstream efforts to combat socially patterned chronic disease.

KEY WORDS: chronic disease; prevention; community health;

self-management support.

$\mathrm{J}$ Gen Intern Med 26(6):658-60

DOI: $10.1007 / \mathrm{s} 11606-010-1606-4$

(C) The Author(s) 2010. This article is published with open access at Springerlink.com

$\mathrm{T}$ he reigning paradigm underlying the work of physicians is evidence-based medicine (EBM). EBM aims to apply the best available evidence gained from the scientific method to medical decision making. It assesses the quality of evidence regarding the risks and benefits of treatments.

Since the early 1990s, EBM has become widely disseminated among medical practitioners and is universally regarded as a major advance in medico-scientific thinking. ${ }^{1}$ One might expect, 10-20 years following such an advance, that the benefits of EBM would have shown up in the population. In some cases, the benefits are clear; for example the percent of patients with myocardial infarction taking beta-blockers has increased substantially. ${ }^{2}$ Yet for a number of conditions, a large proportion of patients remain in poor control despite excellent evidence guiding management and treatment. For two-thirds of Americans with diabetes and half of those with hypertensionconditions with strong evidence-based guidelines-these conditions are inadequately controlled. ${ }^{3,4}$

EBM has two major limitations: 1) the medical care system is not well structured to assist patients in incorporating the advances of EBM into their lives, and 2) the physical and social environment in which patients live create major challenges to patients' ability to make the evidence-based changes required for disease control. We argue that EBM alone is insufficient as a

Received September 1, 2010

Revised November 29, 2010

Accepted December 2, 2010

Published online January 4, 2011 guiding principle for medical practice and that a fundamental shift in thinking is needed. The following few paragraphs explain this paradigm shift.

The Chronic Care Model represents one effort to extend EBM by restructuring primary care, in particular by implementing planned visits-led by nurses, pharmacists health educators or health coaches-that provide patients with the knowledge, skills, and confidence to improve their health behaviors and increase medication adherence. ${ }^{5}$ These services are called "self-management support" (SMS), which has been shown to be the Model's component most commonly associated with outcome improvements. ${ }^{6}$ This is not surprising since patients themselves make the day-to-day decisions regarding chronic conditions. Many SMS models exist, among them the Chronic Disease Self-Management Program in which trained patients lead a group of people with chronic conditions ${ }^{7}$ and the health coaching teamlet in which a trained health coach works closely with a clinician to provide self-management support in the primary care setting. ${ }^{8}$

Thus, SMS can be seen as the work needed to assist patients to incorporate EBM into their lives. One might then hypothesize that adding SMS to EBM leads to better population-wide outcomes. Yet the sum of these two inputs is still insufficient. Patients may try to incorporate EBM into their lives by making the recommended lifestyle changes, regularly monitoring their disease, and adhering to their medications, but often fail because the larger deck - their physical and social environment—is stacked against them. These community-based factors shape both the risk factors they are exposed to and their ability to effectively self-manage. For example, a woman living in a crime-infested neighborhood lacking healthy food outlets, facing barriers to healthy eating and regular exercise, would have great difficulty controlling her diabetes no matter how perfectly the health care team manages the disease and teaches her the knowledge and skills needed for diabetes control.

Efforts to address environmental factors-managing disease at the community level-represent an additional piece to the puzzle. We term such interventions "community health" $(\mathrm{CH})$, meaning policies and actions that address problems in the physical and social environment. Community health entails two types of interventions:

- Individual level interventions that take place in the community. These seek to modify behaviors outside of the clinic doors. An example would be walking groups.

- Community level (structural) interventions that modify the environment in which individuals live. These acknowledge that individuals' behaviors are constrained by larger forces. An example would be increasing the number of safe walking paths in a neighborhood. 
An example that encompasses both categories would be organizing walking groups in an underserved urban area among patients attending a community clinic and assisting the walking group to advocate for new safe park in its neighborhood. $\mathrm{CH}$ has been siloed into the public health domain and has become philosophically and practically estranged from physicians and the medical care system. The focus of public health on the larger context of disease in society contrasts markedly with the medical system's traditional focus on the individual patient. ${ }^{9}$

Physicians correctly argue that before concerning themselves with SMS and $\mathrm{CH}$, they need evidence that these additions to EBM actually improve health. If, indeed, evidence exists supporting the addition of SMS and $\mathrm{CH}$ to EBM, then a new paradigm emerges, superseding EBM. In shorthand, $\mathrm{EBH}=$ $\mathrm{EBM}+\mathrm{SMS}+\mathrm{CH}$.

\section{EVIDENCE SUPPORTING SMS AND CH}

Does evidence exist supporting the effectiveness of SMS and $\mathrm{CH}$ in improving health outcomes? In this brief commentary, we will suggest that such evidence does exist, in particular for diabetes, obesity, asthma, and tobacco use.

Diabetes. A meta-analysis of 31 studies found that selfmanagement support, which involves not only patient education but also the teaching of disease-specific skills, is effective in improving glycemic control. ${ }^{10}$ However, SMS has not been shown to be effective in preventing diabetes. In contrast, a number of studies focusing on community-based interventions directed at preventing diabetes through healthy eating and exercise have shown improvements in not only HbAlc, but cholesterol and weight in patients at risk for diabetes. Central to these efforts have been strategies derived from the Diabetes Prevention Program which place interventions outside medical facilities. ${ }^{11-14}$

Obesity. A Cochrane Review of interventions to change the behavior of professionals and the organization of care to assist overweight or obese adults lose weight, i.e. introducing selfmanagement support in the clinical setting, found inconclusive evidence of success. ${ }^{15}$ Community and schoolbased interventions have shown some success in preventing obesity. ${ }^{16,17}$ Planet Health, a randomized controlled trial for ethnically diverse school children grades 6 through 8, integrated a curriculum delivered by classroom teachers that focused on decreasing television viewing, improving diet, and increasing physical activity. The prevalence of obesity amongst African American girls in intervention schools was significantly reduced. ${ }^{18}$ The Shape Up Somerville intervention, a nonrandomized controlled trial, included three communities studied over a 3-year period and targeted children grades 1 to 3 and their families. The intervention, targeting the before-, during-, and after-school environments included a health education curriculum, physical activity classes, modifications to the school food menu, parent outreach and education, partnering with restaurants to provide healthy food options, and a multimedia outreach campaign. Results after one year showed reduced BMI scores in $1^{\text {st }}-3^{\text {rd }}$ grade children. ${ }^{19}$
Asthma. A meta-analysis of 32 controlled trials of selfmanagement support for children and adolescents with asthma found that these programs significantly reduce school absenteeism, days of restricted activity, nights disturbed by asthma, and emergency department visits. Selfmanagement support involves not only information-giving, but also skills training, self-monitoring, and follow-up. ${ }^{20}$ Community-based interventions may be even more successful if they include both home-based education and elimination of all environmental triggers. ${ }^{21}$

Tobacco use. While a Cochrane Review of physicians, nurses and counselors providing self-management support to smokers found a modest increase in quit rates, ${ }^{22} \mathrm{CH}$ interventions appear more effective than clinical interventions in preventing and reducing tobacco use. A large meta-analysis investigating the effect of public smoking bans showed a $17 \%$ risk reduction in incident acute myocardial infarctions. ${ }^{23}$ A systematic review looking at smoke-free policies in workplaces and indoor public areas found clear evidence that smoke-free policies reduce tobacco use and increase the number of smokers who successfully quit. ${ }^{24}$ Additionally, several studies have noted increases in quit rates when smoking bans are implemented. ${ }^{25,26}$

\section{CONCLUSION}

An emerging literature suggests that evidence-based health, which includes self-management support and community health interventions, can improve outcomes beyond what is possible with evidence-based medicine alone. Implementing evidence-based health requires a re-imagining of the interface between clinical care and community-level interventions. The medical care system, largely focused on individual patients, has not paid sufficient attention to the physical and social environment in which its patients live their lives. As the rates of chronic diseases increase, inattention to these factors will lead to a disease burden that outpaces the scope and resources of the medical care system.

Evidence-based health requires embracing a broad definition of the causes of health and illness that extends beyond clinic doors. An example worth remembering is the Mound Bayou Mississippi community health center founded in 1967, which offered not only primary care but also implemented sanitary water supplies, fair loan practices by local banks allowing residents to build new homes, a bus system for transportation, a nutritional program for pre-school children, and a farming cooperative. ${ }^{27}$ These up-stream interventions-termed "community-oriented primary care"-were integrated with clinical care in a way that addressed the multiple causes of poor health, wholly acknowledging the role of environmental factors.

The patient-centered medical home concept hopes to invigorate primary care in the US. It includes self-management support as one of its functions but does not emphasize community health. ${ }^{28}$ Several organizations are advocating for a health home rather than a medical home, mirroring the distinction between EBH and EBM. ${ }^{29}$

Some authors have pleaded that primary care practices tear down the silos and integrate with the public health community. Such entreaties fail to grasp the difficulties in doing so. A 
paradigm shift from evidence-based medicine to evidence-based health requires a transformation even more profound than what is needed to move traditional primary care practice into a patientcentered medical home. To implement evidence-based health, not only would practices need to create population-oriented, team-based, prompt-access, cost-controlled, and physiciansatisfied care to become medical homes; they would need to do all these things plus extend their purview to community-based prevention. To do these things would require major changes in payment such that primary care practices are financially rewarded for engaging in both self-management support and community health.

This journey can begin with small steps, starting with the more actionable individual-level interventions placed outside the clinic walls and moving later to structural interventions that modify the community environment. The job description of one person in a primary care practice-perhaps a medical assistant-could be changed to require the development of a referral process to community-based healthy eating and exercise programs for all patients with obesity, diabetes, pre-diabetes, and hyperlipidemia. Primary care training programs and board exams could require detailed understanding of the Diabetes Prevention Program and include patient education on diabetes prevention as an integral part of health care maintenance counseling. Medicare could add a reimbursement code for care coordination with community-based prevention services. Practices could train patients with diabetes as peer educators who also serve as community advocates to improve the health-related environment in the neighborhoods served by the practice. NCQA accreditation could be broadened to require primary care practice involvement in modifying structural risk factors in the neighborhood surrounding the practice; for example, advocating for stronger tobacco-free area policies or regulating asthma-associated industrial emissions. All of these activities would require payment reform that rewards team-based care; practices cannot be expected to engage in these activities without reimbursement. While the implementation of evidence based health poses substantial challenges, the first step needs to be the medical profession's acceptance of the evidence-based health paradigm. Without such agreement, the medical-public health silos continue as before, unchanged and unchangeable.

Acknowledgement: Funding was from the California Endowment.

\section{Conflict of Interest: None disclosed.}

Open Access: This article is distributed under the terms of the Creative Commons Attribution Noncommercial License which permits any noncommercial use, distribution, and reproduction in any medium, provided the original author(s) and source are credited.

Corresponding Author: David Moskowitz, MD; Division of General Internal Medicine, University of California San Francisco, 3333 California Street, Room 383, Box 1211, San Francisco, CA 94143 1211, USA(e-mail: david.moskowitz@ucsf.edu).

\section{REFERENCES}

1. Eddy DM. Evidence-based medicine: a unified approach. Health Aff (Millwood). 2005;24(1):9-17.

2. Lee TH. Eulogy for a quality measure. N Engl J Med. 2007;357(12):1175-7.

3. Saydah SH, Fradkin J, Cowie CC. Poor control of risk factors for vascular disease among adults with previously diagnosed diabetes. JAMA. 2004;291(3):335-42.
4. Egan BM, Zhao Y, Axon RN. US trends in prevalence, awareness, treatment, and control of hypertension, 1988-2008. JAMA. 2010;303 (20):2043-50.

5. Bodenheimer T, Wagner EH, Grumbach $\mathbf{K}$. Improving primary care for patients with chronic illness: the chronic care model, Part 2. JAMA. 2002;288(15):1909-14.

6. Pearson M, Mattke S, Shaw R, Ridgely M, Wiseman S. Patient selfmanagement support programs: an evaluation. Rockville, MD: Agency for Healthcare Research and Quality; 2007.

7. Lorig KR, Ritter P, Stewart AL, et al. Chronic disease self-management program: 2-year health status and health care utilization outcomes. Med Care. 2001;39(11):1217-23.

8. Chen EH, Thom DH, Hessler DM, et al. Using the Teamlet Model to improve chronic care in an academic primary care practice. J Gen Intern Med. 2010;25(Suppl 4):S610-4.

9. Satcher D, Higginbotham EJ. The public health approach to eliminating disparities in health. Am J Public Health. 2008;98(3):400-3.

10. Norris SL, Lau J, Smith SJ, Schmid CH, Engelgau MM. Selfmanagement education for adults with type 2 diabetes: a meta-analysis of the effect on glycemic control. Diabetes Care. 2002;25(7):1159-71.

11. Ackermann RT, Finch EA, Brizendine E, Zhou H, Marrero DG. Translating the Diabetes Prevention Program into the community. The DEPLOY Pilot Study. Am J Prev Med. Oct. 2008;35(4):357-63.

12. Amundson HA, Butcher MK, Gohdes D, et al. Translating the diabetes prevention program into practice in the general community: findings from the Montana Cardiovascular Disease and Diabetes Prevention Program. Diabetes Educ. 2009;35(2):209-10.

13. Cramer JS, Sibley RF, Bartlett DP, Kahn LS, Loffredo L. An adaptation of the diabetes prevention program for use with high-risk, minority patients with type 2 diabetes. Diabetes Educ. 2007;33(3):503-8.

14. Mayer-Davis EJ, D'Antonio AM, Smith SM, et al. Pounds off with empowerment (POWER): a clinical trial of weight management strategies for black and white adults with diabetes who live in medically underserved rural communities. Am J Public Health. 2004;94(10):1736-42.

15. Flodgren G, Deane K, Dickinson HO, et al. Interventions to change the behaviour of health professionals and the organisation of care to promote weight reduction in overweight and obese people. Cochrane Database Syst Rev. 2010;3:CD000984.

16. Sallis JF, Glanz K. Physical activity and food environments: solutions to the obesity epidemic. Milbank Q. 2009;87(1):123-54.

17. Story M, Nanney MS, Schwartz MB. Schools and obesity prevention: creating school environments and policies to promote healthy eating and physical activity. Milbank Q. 2009;87(1):71-100.

18. Gortmaker SL, Peterson $\mathbf{K}$, Wiecha $\mathbf{J}$, et al. Reducing obesity via a school-based interdisciplinary intervention among youth: Planet Health. Arch Pediatr Adolesc Med. 1999;153(4):409-18.

19. Economos CD, Hyatt RR, Goldberg JP, et al. A community intervention reduces BMI $z$-score in children: Shape Up Somerville first year results. Obesity (Silver Spring). 2007;15(5):1325-36.

20. Guevara JP, Wolf FM, Grum CM, Clark NM. Effects of educational interventions for self management of asthma in children and adolescents: systematic review and meta-analysis. BMJ. 2003;326(7402):1308-9.

21. Wu F, Takaro TK. Childhood asthma and environmental interventions. Environ Health Perspect. 2007;115(6):971-5

22. Lai DT, Cahill K, Gin Y, Tang JL. Motivational interviewing for smoking cessation. Cochrane Database Syst Rev. 2010(1):CD006936.

23. Meyers D, Neuberger JS, He J. Cardiovascular Effect of Bans on Smoking in Public Places. J Am Coll Cardiol. 2009;54(14):1249-55.

24. Hopkins DP, Razi S, Leeks KD, Priya Kalra G, Chattopadhyay SK, Soler RE. Smokefree policies to reduce tobacco use. A systematic review. Am J Prev Med. 2010;38(2 Supp):S275-89.

25. Moskowitz JM, Lin Z, Hudes ES. The impact of workplace smoking ordinances in California on smoking cessation. Am J Public Health. 2000;90(5):757-61.

26. National Institutes of Health. Smoking and Tobacco Control Monograph No. 10: Health effects of exposure to environmental tobacco smoke: The report of the California Environmental Protection Agency: US Department of Health and Human Services. NIH publication no. 99-4645; 1999.

27. Geiger HJ. Community-oriented primary care: a path to community development. Am J Public Health. 2002;92(11):1713-6.

28. Landon BE, Gill JM, Antonelli RC, Rich EC. Prospects for rebuilding primary care using the patient-centered medical home. Health Aff (Millwood). 2010;29(5):827-34.

29. Schor EL. From medical home to health home. J Gen Intern Med. 2010;25(11): 1144 